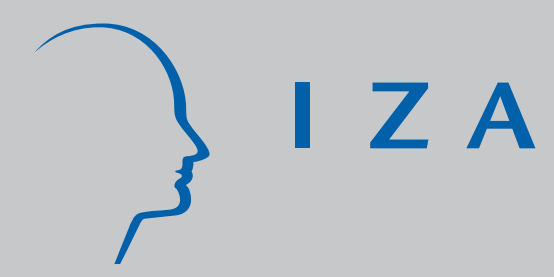

IZA DP No. 4109

Hostility Toward Immigration in Spain

Ferran Martínez i Coma

Robert Duval-Hernández

April 2009 


\title{
Hostility Toward Immigration in Spain
}

\author{
Ferran Martínez i Coma \\ CIDE
}

Robert Duval-Hernández

CIDE and IZA

\section{Discussion Paper No. 4109 \\ April 2009}

\author{
IZA \\ P.O. Box 7240 \\ 53072 Bonn \\ Germany \\ Phone: +49-228-3894-0 \\ Fax: +49-228-3894-180 \\ E-mail: iza@iza.org
}

\begin{abstract}
Any opinions expressed here are those of the author(s) and not those of IZA. Research published in this series may include views on policy, but the institute itself takes no institutional policy positions.

The Institute for the Study of Labor (IZA) in Bonn is a local and virtual international research center and a place of communication between science, politics and business. IZA is an independent nonprofit organization supported by Deutsche Post Foundation. The center is associated with the University of Bonn and offers a stimulating research environment through its international network, workshops and conferences, data service, project support, research visits and doctoral program. IZA engages in (i) original and internationally competitive research in all fields of labor economics, (ii) development of policy concepts, and (iii) dissemination of research results and concepts to the interested public.
\end{abstract}

IZA Discussion Papers often represent preliminary work and are circulated to encourage discussion. Citation of such a paper should account for its provisional character. A revised version may be available directly from the author. 


\section{ABSTRACT}

\section{Hostility Toward Immigration in Spain}

This paper provides new evidence regarding public opinion on immigration by studying the Spanish case, and by analyzing not only respondents' preferences regarding immigration levels, but also regarding admittance policies and the rights and benefits to grant to foreigners. In general, Spaniards support less immigration, and more selectivity based on skills and qualifications, but not reduced rights and benefits for immigrants. Skilled natives have more positive attitudes about immigration, in spite of the potential fiscal burden it implies for them. Respondents believing that immigration drops natives' wages tended to oppose immigration and endorse reducing the benefits and rights granted to immigrants. More negative attitudes were found among individuals who dislike other races, while the opposite was found for those valuing cultural diversity. Catholic respondents favor more restrictive admission policies, in particular ones based on cultural factors. Respondents in provinces with high immigration and a high proportion of Moroccans wanted lower levels of immigration, though having contact with immigrants reduces the negative attitudes toward them. Individuals overestimating the levels of immigration are more prone to have negative attitudes toward immigrants.

JEL Classification: F22, J61

Keywords: international migration, immigration preferences

Corresponding author:

Ferran Martínez i Coma

Centro de Investigación y Docencia Económicas, A.C.

Carretera México-Toluca 3655

Col. Lomas de Santa Fe

01210 México, D.F

México

E-mail: ferran.martinez@cide.edu

\footnotetext{
* The authors would like to thank Ignacio Sánchez-Cuenca and seminar participants at "II Seminario de Doctores" at Juan March Institute and at CIDE. All remaining errors are our sole responsibility.
} 


\section{Introduction}

Many papers studying attitudes toward immigrants and immigration policy rely on survey questions asking if the respondent would like to see the current levels of immigration increased, decreased, or stabilized. ${ }^{1}$ In particular, the literature has focused on studying to what extent economic, identitary, personal contact and information factors affect the public opinion concerning the number of immigrants in a given country.

While such studies have produced interesting results, they have the limitation of focusing on a single dimension of the relationship between public opinion and immigration, namely whether or not the number of immigrants in any given country is appropriate. However, in practice, such a relationship is clearly not reduced to just this aspect, and many important questions remain unanswered in the literature.

For instance, it would be interesting to study what type of immigration the public wants and what the determinants of these preferences are. It would also be interesting to study the public opinion toward rights granted to immigrants. Are the preferences for granting political rights aligned with granting costly benefits, like education or health? Furthermore, does the validity of the hypotheses studied in the literature still hold once we focus on these other dimensions of pubic opinion?

This paper overcomes some of the aforementioned limitations by using a rich dataset on public opinion on immigration for Spain. The data allows us to answer some of the

\footnotetext{
${ }^{1}$ See, for instance, Espenshade and Hempstead, 1996; and Citrin and Sides, 2007.
} 
previous questions and to achieve a more complete view of the relationship between immigration and public opinion.

Another goal of this paper is to analyze the Spanish case, which is underrepresented in the literature on public opinion and immigration. While other papers have covered many other European and non-European countries, Spain has not received as much attention, in spite of its high immigration rates. ${ }^{2}$ Furthermore, studying the Spanish case in detail allows us to assess whether opinions toward immigration vary depending on the region and on the type of immigrants in question.

In the second section of the paper, we review the different explanations linking public opinion and immigration. Section 3 discusses some of the motivations that make the Spanish case worth studying separately. In the fourth section, we present our variables and dataset, and in section 5 we discuss the estimation methods employed. Section 6 presents the results, and section 7 concludes.

\section{Theory and Previous Literature}

The relationship between immigration and public opinion is normally approached from two perspectives, labeled by some as the economic and the identitarian. The economic perspective reflects voters' economic interests, while the identitarian may include "racism, xenophobia and milder forms of nationalist sentiment such as social norms or cultural preferences” (O’Rourke and Sinnott, 2005: 839). There are, however, two additional factors worth analyzing that have received minor attention in the literature.

\footnotetext{
2 The paper by Escandell and Ceobanu (2009) is a notable exception to this claim.
} 
One stresses the role of natives' interactions with immigrants, in what is known as the 'contact hypothesis', while the other focuses on the actual information that natives have about immigration. The introduction of those explanations is important because attitudes toward immigration are based on the natives' perceptions as well as actual facts about immigration. The following subsections discuss these four hypotheses in more detail.

\subsection{Economic explanations}

The literature provides two broad explanations for why economic factors may trigger negative attitudes toward immigration.

The first of these is the economic threat, the effect of which is independent of whether it is real or imagined. For instance, following and adapting from ethnic competition theory, competition is more intense when immigrants are employed in the same jobs or sectors as natives. Hence, if the newcomers overlap in the economic niche of the locals, the locals will reject the foreigners (Olzak, 1992). From a competing and adapted explanation, the ethnic segregation model, Hecther (1975) suggests that the concentration of a concrete ethnic group in low-status occupations leads to increased immigrant solidarity and political mobilization. When faced with such mobilization, the locals may react even more negatively toward immigrants.

The second explanation for why economic factors may trigger negative attitudes toward immigration is provided by Runciman’s (1966) and Gurr's (1970) relative deprivation theory. According to this theory, "at some point in time, people might notice that they want more than they have and have less than they feel rightfully entitled to (wanting and 
deserving in Crosby's, 1982, revised model), resulting in feelings of relative deprivation such as anger, grievance, moral outrage, or resentment.” (Mummendey, et. al. 1999:229). Runciman distinguished between personal or egoistic and group-specific or relative deprivation. While the former comes from the comparison with other individuals, the later is rooted in the comparisons of one's own group with other relevant social groups. In this sense, immigrants, both as individuals and as a group, could generate such grievances, explaining the negative attitudes toward them. Given those two potential economic explanations, we should be more precise and specify the mechanisms leading to a negative perception of immigration.

The first hypothesis that we introduce is labeled the "resource hypothesis". This hypothesis posits that "people who are experiencing financial stress will be more likely than the well-off to fear the implications of immigration” (Citrin et al. 1997:860). Hence, those persons in a difficult economic situation and/or who are insecure about their future should have more negative attitudes toward immigrants who are perceived as potential economic competitors. Mixed evidence supporting this hypothesis has been mainly obtained for the North American case (Citrin, Reingold, and Green, 1990; Espenshade and Calhoun, 1993; Hoskin, 1991; Hanson, Scheve, and Slaughter, forthcoming).

The negative perception of immigration will be reinforced among native workers facing higher competition in the labor market due to the presence of immigrants of similar skill levels. This explanation is known as the "job threat" hypothesis (Facchini and Mayda 2006). In the case of Spain, where immigrants have lower skill levels on average than the typical native (Cachón, 2000; Corkill, 2001; Dolado, 2002; Solé and Parella, 2003), it is 
expected that poorer, uneducated natives will have more hostile attitudes toward immigrants.

A second hypothesis, known as the "pessimism hypothesis", highlights the role of individuals' perceptions regarding economic change. Independent of one’s economic level, the hypothesis states that "the belief that one is on a downward economic trajectory increases the tendency to view immigration as resulting in tangible costs to oneself and enhances restrictionist sentiment” (Citrin et. al. 1997: 860-861). Hence, prospective as well as retrospective perceptions of one's personal economic situation may be included in the analysis.

Finally, individuals may have 'res publica' considerations when thinking about immigration. In this logic, if immigration is perceived as increasing the expense of public services and has negative consequences for public finances, this will create a negative attitude toward it.

This is known as the "fiscal burden" hypothesis, and there are two intertwined facets to consider. On the one hand, relatively poor natives will oppose immigration because resources are scarce and immigrants might compete with them for public services and benefits. On the other hand, wealthier natives might have a negative perception about immigrants because they might increase the cost of providing public services, causing their taxes to increase. ${ }^{3}$

\footnotetext{
${ }^{3}$ This topic has been studied extensively for the U.S. case; see for instance Borjas and Hilton, 1996; Borjas, 1999; Fix and Passel, 2002; Hanson, 2005; and Hanson, Scheve and Slaughter, forthcoming.
} 


\subsection{Identity explanations}

In analyzing the relationship between immigration and public opinion, it is important to consider a set of 'national identity' factors since “immigration is a 'special' policy area, because of its links with the actual definition of the nation itself” (Luedtke, 2005:86). Indeed, immigration policy lies at the heart of the definition of citizenship and national identity.

The problem, of course, is defining 'national identity,' since 'there is a lack of standard and commonly accepted definitions and measures' (Christin and Trechsel, 2002:417). We follow Luedtke (2005), who relies on the field of social psychology and defines identity “in a social sense, as an affective state of belonging to a social group” (87). ${ }^{4}$ Evidently, those evaluations can be positive as well as negative - like ‘in-group love' and 'out-group hate' (Brewer, 1999; Brown, 2000). This definition is very much linked with one of the premises of social identity theory: a basic element of the individual's sense of self is based on which groups they identify with or belong to (Tajfel, 1981), and normally, they will evaluate their own group positively and the other - although not always (Brewer, 2001) - negatively.

It must be noted that this concept of national identity, although politically very powerful, is, from an academic perspective, very weak given its main component, the nation. Independent of the definition that we agree on, it is very clear that "the impact of concerns about national identity is conditional on the prominence of the differences between groups" (Sniderman, Hagendoorn and Prior, 2004: 36). In this regard, the

\footnotetext{
${ }^{4}$ The affective state is defined as "opposed to a cognitive state, is one that can independently generate social preferences, leading to emotional evaluations of social groups” (Luedtke, 2005:87).
} 
literature identifies three important factors: perceptual distinctiveness, salience and entativity, which is the perceived internal cohesiveness of a group (Campbell, 1958).

First, immigrants may stand out because many have a different skin color (like subSaharan Africans, Chinese, Moroccans and some Latin Americans), dress differently and lack fluency in Spanish. Regarding salience, immigrant cultural distinctiveness has been gaining media coverage since the mid-nineties. Finally, regarding entativity, immigrants tend to be concentrated in certain areas of Spain and, in some cases, have strong family and group loyalties, common beliefs and distinctive cultural practices.

Opinions about immigration should also be influenced by beliefs about what cultural unity and national identity are. If natives believe that immigrants' culture threatens the idiosyncrasy of their country or its way of life, opposition to immigration should be higher than otherwise.

The elements that have traditionally articulated the concept of national identity are, among others, language, religion and race (Smith, 2001). An umbrella term normally used for those factors is 'culture'. Surveys, such as the one we used for our analysis, normally include questions that allow us to address them under the 'culture' label. Given that language, religion and race are very intertwined factors, we argue that the label 'culture' will encompass all of them. 


\subsubsection{The Muslim Factor}

Building on the national identity theory, we propose a second specific addition to the debate that is particularly relevant for the Spanish case. The basic idea is that not all immigrants are the same, and that the existence and distribution of a specific group of immigrants in a higher relative proportion affects general perceptions about immigration. For the Spanish case, this specific group is Muslims. ${ }^{5}$

Citrin and Sides (2006:328) provide a theoretical justification of this when claiming that “if descent or cultural affinity is what creates the 'imagined community' that is a nation (Anderson, 1983) then the immigration of mainly non-white and Muslim populations poses a threat to the very identity of people”. This claim is not enough to justify, for instance, why Chinese immigrants are not singled out, given that they are non-white and non-Christian.

A first possible explanation lies in the relative sizes of immigration flows per group. Although losing relative weight with regard to the total population, Muslim immigrants have been the main non-European immigrant group in Spain. ${ }^{6}$ According to the 2006 Census, of the 4,111,166 immigrants in Spain, 563,012 (or 13.59\%) were Moroccans.

Furthermore, a look at the distribution of Moroccan immigrants at the regional level shows important disparities. In provinces like Asturias, they do not reach 5\% of the immigrant population. However, in regions like Cáceres, they represent $55 \%$ of all

\footnotetext{
${ }^{5}$ A similar claim has been made for the U.K. by Dustman and Preston (2000), who found that attitudes toward foreigners from other European countries were more favorable than toward Asians or West Indians. ${ }^{6}$ Ecuadorians in turn are becoming a more important group over time.
} 
immigrants. Such stark differences in regional distribution are likely to have an effect on attitudes about immigrants.

These negative attitudes have also been reflected in the declarations of public officials. For instance, in 1991 Jordi Pujol, former President of the Catalan Autonomous Government, said: "In Catalonia, as in any European country, it is easy to integrate the Polish, Italians or Germans, but it is difficult to achieve that with Arab Muslims, even with those who are not fundamentalists” (Ortuño Aix, 2006:236). Furthermore, those claims have not come only from the conservative and nationalist right parties, but also from political groups on the left. ${ }^{7}$ Unfortunately, the problems have not been limited to words. In Terrassa, Catalonia, where 20.64\% of immigrants are Moroccan, and El Ejido in Almeria, where $30 \%$ of immigrants are Moroccan, Muslim immigrants have been 'hunted down' and lynched by organized groups of locals.

In sum, we have presented two different hypotheses to test the identity theory. The first will look at typical cultural factors as possible determinants of preferences toward immigrants. The second considers that both the amount and the distribution of immigrants around the country have an effect on people's attitudes toward immigration and that Muslim immigrants are a particular group that stands out in comparison to other immigrants.

For the rest of the paper, we will proxy Muslim immigration by looking at Moroccans as a group. Evidently, Algerians or other Maghrebians could also be included in the group.

\footnotetext{
${ }^{7}$ In 2001, former General Secretary of the independentist Esquerra Republicana de Catalunya (Republican Catalan Left) Heribert Barrera declared: "if the present migratory flows go on like this, Catalonia will disappear” (El Pais, 27 ${ }^{\text {th }}$ February 2001).
} 
However, given the importance of Moroccan migration among the total number of Muslim migrants, this distinction is of secondary importance.

\subsection{Contact Explanation}

Beyond the economic and the cultural/identity explanations, another factor that may influence the general public's perceptions of immigration is the contact that individuals have with immigrants in their daily lives.

This is not a new hypothesis. Actually, it was first posed by Williams (1947) and was revised later by Allport (1954) and many others. However, the focus was mainly the U.S., where it was used in an attempt to explain hostility and prejudice toward blacks, while only recently has evidence begun to appear for some European cases (Masson and Verkuyten, 1993; Pettigrew 1998; McLaren 2003; Wagner, et. al., 2003).

By 'contact', we mean the relationships that the natives have with the immigrants in a direct way. The argument that contact would increase positive attitudes toward immigrants can be framed as a result of Axelrod's (1983) and Putnam's (1993) work. As the different actors (locals and immigrants) interact over time, cooperation emerges, creating a virtuous circle. Such interactions are associated with a positive perception about the immigration phenomenon. ${ }^{8}$

However, such a positive relationship does not always arise in practice (as recognized by Putnam, 1993 and Boix and Posner, 1996). In particular, not all of the established contacts are among equals, nor are they based on a democratic relationship. For example,

\footnotetext{
${ }^{8}$ Research by Espenshade and Calhoun (1993) finds that Americans may have negative attitudes toward immigration as a general phenomenon, but sympathy for those they personally know.
} 
given that the immigrants are mainly oriented toward low-skilled jobs, they will be in an unequal position compared to their employers.

Second, one must also consider the nature of the contact or, as Burns and Gimpel state, "presumably, interaction in the workplace is qualitatively different from interaction in other settings such as neighborhood, church or school” (2000: 209). For example, the attitudes that any given individual has toward immigrants will differ depending on whether his or her contact with the immigrants is based on a love, work or neighborhood relationship. For all of these reasons, we distinguish between active and passive contact. Active contact is defined as contact in which the native plays a definitive role for such contact to take place, while in the passive case, the interaction is accidental. In the former category, we could include those natives who have immigrant romantic partners or friends, while in the latter would be coworkers. In general, we hypothesize that the former is more likely to generate a positive attitude toward immigrants than the latter.

To sumarize, interaction with immigrants may help natives to know them better and can reduce biases, fostering trust and positive feelings toward immigration. Such attitudes are more positive when the native's role is active rather than accidental. On the other hand, the contact experience may be negative and enhance those negative views toward immigration. As will be seen below, in this 2x2 matrix (active/passive, positive/negative) we are only able to distinguish between active and passive contact. To disentangle whether a given contact is positive or negative, more qualitative data is necessary. 


\subsection{Information Explanation}

Another factor that we introduce here is the actual information that natives have about immigrants. People tend to overestimate the numbers of minorities present in a country (Nadeau, Niemi and Levine, 1993; Sigelman and Niemi, 2001). For example, TheissMorse (2003) shows that while the 2000 U.S. Census fraction of African-Americans is $12 \%$ of the total population, respondents estimate it to be around $39 \%$. Overestimation also occurs for Hispanics (12\% versus 33\%), Asians (4\% versus 24\%) and Jews (2.5\% versus 26\%). As will be seen below, a similar phenomenon occurs for our dataset from Spain.

In reality, there is always a gap between perceptions and real facts. However, in the case of immigration, such a gap might be associated (both as a cause and as an effect) with the attitudes the public holds on the issue. In fact, this fact provided the impetus for Sides and Citrin (2007) to run two different survey experiments to test how informing people about immigrants affects their attitudes toward them.

The gap between perceptions and reality about immigrants can be either positive or negative. In the cases with no difference, the perception and the reality would be perfectly matched, and information and perception would go hand in hand. Our argument is that the aforementioned gap may condition opinions about a specific issue (in this case, immigration). For instance, the more natives overestimate the number of immigrants, the more likely they will be to express negative attitudes toward this group. When the gap is 
close to zero, we would expect a 'genuine' opinion about immigration not mediated by subjective perceptions. $^{9}$

To conclude, the expectations are that when there is an overestimation (under) of the number of immigrants, this will be associated with a negative (positive) opinion about immigration.

\subsection{Previous Studies for Spain}

The paper by Escandell and Ceobanu (2009) is, to the best of our knowledge, the only study on public opinion and immigration focusing exclusively on Spain. Their paper examines the 'contact hypothesis' and theories of 'group threat' in Spain for the period of 1991-2000. In particular, they investigate whether having contact with African and Latin American immigrants reduces the expressed exclusionism of the respondents. Using different contact measures and after multiple individual- and contextual-level controls, they find that close and occasional forms of contact are associated with reduced foreigner exclusionism. However, workplace contact has no such effect. Second, the perceived number of people with different nationality, race, religion or culture (a proxy for group threat) contributes considerably to explaining variation in attitudes between regions.

\section{Why Spain?}

During the first half of the twentieth century, Spain (as well as Italy, Greece and Portugal) was a country sending migrants abroad. However, by the second half of the

\footnotetext{
${ }^{9}$ This distinction is key both in academia and in politics. From the academic perspective, it is important to know if one's opinion on issue A is mediated by another opinion or by actual information. From a political perspective, this distinction is even more important since such opinions can affect policy outcomes.
} 
nineties, a shift started whereby "migrants who were trying to reach other European countries especially from North Africa, found it easier to slip into southern Europe; many stayed in their country of entry” (McLaren, 2003: 910).

Adding to this, the economic growth experienced by the region increased the incentives for immigration. Among southern European countries, Spain experienced the highest economic growth. ${ }^{10}$ As a result, Spain has been receiving more immigrants than any other country in Europe. Beyond the North African migration, Spain has received the most Latin American citizens, a phenomenon in part explained by their historical ties and common language.

Figure 1 shows the immigrant fraction of the population and the net immigration rates for European countries plotted against the percentage of respondents to the Eurobarometer's 64.2 (2005) question: "What do you think are the two most important issues facing (OUR COUNTRY) at the moment?”

As can be seen, of the countries in the sample, Spain has the highest rate of public concern about the immigration issue. In fact, respondents rated "unemployment" as the most important issue in almost every country except Denmark, Spain, Ireland, Malta and the United Kingdom, where “immigration” was deemed more important.

\section{FIGURE 1 ABOUT HERE}

The figure also shows that while there does not seem to be a relationship between public concern about immigration and the fraction of immigrants in the population, there is a

\footnotetext{
${ }^{10}$ In fact, with the exception of Ireland, Spain is the country with the highest economic growth in the last 10 years in Europe.
} 
clear correlation between such public concern and the net immigration rates. Yet, in both pictures, Spain stands as an outlier in the degree of concern over immigration in the country. ${ }^{11}$

There are other factors that justify the study of Spanish public opinion toward immigration.

Some authors have claimed that "the issue of immigration control is seldom a high priority for voters, and the issue's salience depends largely on whether politicians draw public attention to it” (Karapin, 1999: 425). In Europe, “national politicians are unlikely to do so because they usually participate in a consensus in which they tacitly agree to uphold liberal immigration policies and not to appeal to the anti-immigrant sentiments of the public" (Karapin, 1999: 425). In Spain, immigration has been debated in recent election campaigns both at the local (2007) and national (2008) levels. Also, important political and civic figures have talked about the issue recently. The day the new Minister for Labor and Immigration (from the Spanish Socialist Party) assumed office, he stated: "In this country, (we'll accept) all the immigrants that are necessary, but all with a work contract” (El Pais: April 14 ${ }^{\text {th }}$, 2008).

Besides the clear academic relevance, there are clear policy implications to our study. In particular, understanding which hypotheses better explain the attitudes toward immigration can give us insights into the immigration and welfare policies that could be implemented in the near future.

\footnotetext{
${ }^{11}$ The only other country in the sample with a higher net migration rate is Cyprus. However, in this case the public attitudes toward immigration are much milder, probably because in this country the high migration flows of the last years have been promoted by the government to counteract labor force shortages (Christofides et. al., 2007; Eliofotou, 2008).
} 


\section{Data}

The data used in this study are the "Barómetro de Noviembre” provided by the Centro de Investigaciones Sociologicas for November of 2005. The survey is a nationwide sample of the population 18 years of age and older. The sample covers 47 provinces, and the sampling procedure is multi-stage stratified by clusters. The questionnaires were applied through direct interviews at the home of the interviewees.

As mentioned, we have four dependent variables. The first asks whether the immigration

levels are high, low or about right. ${ }^{12}$ In particular, it asks "The number of people coming from another country... Do you think it is not a lot, a lot but not too many, or too many?” We will take this variable to reflect the desired level of immigration of the respondent.

The second dependent variable is related to the type of immigration desired. The specific question asks, "How important should each of the following aspects be in order to allow a foreigner to live here?” Several options are offered, such as: being well educated, having family members already living in Spain, speaking Spanish, being from a Christian country, being of white race, being wealthy, and having a labor qualification needed in Spain. The response options range from 0 to 10 according to the importance attached to each option. Since language, religion, and race reflect the importance of cultural factors and they are highly correlated among themselves, they were grouped into a single dependent variable that was constructed by averaging the answers to these three

\footnotetext{
${ }^{12}$ This question is very similar to the one posed by the Eurobarometer 47.1 (1997).
} 
characteristics. ${ }^{13}$ Hence, for the type of immigration desired, we will test our models for education, family, culture, wealth and labor required in Spain. Although being 'highly skilled' and having the 'labor qualifications needed in Spain' could potentially indicate similar characteristics, we include them as separate dependent variables because in principle, an individual might favor admitting low-skilled immigrants if he/she believes that unskilled labor is needed in the market. ${ }^{14}$

The third and fourth dependent variables are linked with rights and benefits granted to immigrants. In our approach, we recognize that not all rights are the same, so we differentiate among them. On the one hand, there are political and social rights, like voting or the right to freely practice a religion. A particular characteristic of these rights is that the individual access to them does not affect the access to such rights by other citizens. Immigrants normally lack such 'political' rights, and natives vary in the degree of their support for the expansion of political rights to immigrants. Consequently, our third variable is whether the respondent agrees or not with the expansion of political and social rights to immigrants. ${ }^{15}$

On the other hand, there are rights related to the welfare state, like education and health. In a country like Spain, those are universal rights, so everybody has the right to receive them. One of the most important differences between political and social rights and welfare benefits is that the latter imply an economic cost to natives. Hence, reactions to

\footnotetext{
${ }^{13}$ The Cronbach's alpha among the language, race and religion factors is 0.7 , which is a reliable consistency coefficient indicating that these three factors measure a common underlying 'cultural' component.

${ }^{14}$ The correlation coefficient between these two variables is less than 50 percent; see Table A-2 in the Appendix.

${ }^{15}$ The variable includes the right to: bring his own family along, have equal conditions in the workplace, freely practice his own religion, form associations to defend their rights, vote in municipal elections, vote in general elections, join political parties or unions, and eventually be able to apply for Spanish citizenship.
} 
the expansion of welfare benefits can be very different among natives, as Hanson (2005) has shown for the US case. In particular, the fiscal burden hypothesis implies that, ceteris paribus, a higher opposition to immigration will be observed among those segments of the native population who bear the costs of providing such economic benefits. Our last dependent variable will then be whether the respondent agrees or not with the expansion of welfare benefits, in particular access to health care and access to public education for immigrants or their children.

Figures 2 to 4 present the responses to the aforementioned dependent variables.

\section{FIGURE 2 ABOUT HERE}

Figure 2 shows that in general, the sampled population thinks that the current number of immigrants in Spain is too large. Indeed, about $60 \%$ of the respondents think that there are too many immigrants. About one third of them think there are 'a lot, but not too many', and only a minority of 3\% think that the number of immigrants is not large. The rate of non-response is small. By the wording of the question, it is fair to infer that those who answered the question indicating that there are 'too many' immigrants would like to see the current immigration levels reduced.

\section{FIGURE 3 ABOUT HERE}

Figure 3 contains the response rates for what the requirements for immigrants should be to be allowed to live in Spain. The responses range from 0 to 10 , with a response of 0 indicating that a given factor is not important and a response of 10 indicating that the requirement is crucial. 
The figure shows that the requirements that matter most for the public are having a particular qualification needed in the Spanish labor market, education, and, to a lesser extent, family ties. Although cultural affinity matters, it does not receive much weight in the eyes of the respondents. Finally, being wealthy is a factor that matters little, as $50 \%$ of the respondents think that this factor should not matter at all in deciding which immigrants are allowed to live in Spain.

\section{FIGURE 4 ABOUT HERE}

Finally, Figure 4 shows that the majority of the respondents support offering the maximum number of welfare benefits (health and education) and social and political rights (e.g., voting in elections, right to practice their religion, etc.) to immigrants. ${ }^{16}$

In summary, this descriptive look at the different dependent variables shows that respondents tend to think that the number of immigrants is too large and that immigrants should be selected mainly based on their qualifications and the skills needed in the Spanish labor market, yet in general, they support giving a broad range of welfare benefits and social and political rights to foreigners in the country.

\section{Estimation}

To gain a better understanding of what lies behind such preferences, a regression analysis was performed. This analysis can not only uncover determinants of the different opinions about immigration, but can also serve to empirically test some of the aforementioned hypotheses.

\footnotetext{
${ }^{16}$ The fact that almost a third of the sample did not respond to all of the questions about social and political rights might be due to the ambiguity of some of the questions.
} 
In particular, three models are estimated for each dependent variable. In the first group of estimations, the independent variables $\mathrm{X}$ are a set of variables that can be considered exogenous to the dependent variable. This group of variables includes: gender, age, education level, marital status, religion ${ }^{17}$, occupation type (blue collar, service or white collar), employment status, immigration rate at the province level, fraction of immigrants of Moroccan descent at the province level, province's GDP per capita, and a dummy variable for regionalist autonomous community (Catalonia, Galicia and País Vasco).

A second set of estimations includes, in addition to the previous variables, other variables that could potentially be endogenous to the stated preference toward immigration. These variables ask whether the respondent believes immigration: reduces natives' wages, negatively affects the poor andlor helps fill vacant jobs, or whether s/he: has a preference for living in a culturally diverse environment, prefers not having an immigrant as a boss or married to a close relative, has contact with immigrants through work, friendship or as a neighbor. Finally, a third group of estimations included all of the aforementioned variables plus the perceived fraction of immigrants in the population, a variable that will serve to test the information hypothesis. This final set of estimations is performed separately because there is a high non-response rate on the perceived number of immigrants variable.

While the set of additional variables included in the last two models could potentially be endogenous to the stated preference on immigration, including these variables in the empirical estimations will show the relations between these factors and the dependent

\footnotetext{
${ }^{17}$ In principle, religion could potentially be endogenous, yet in a country where two thirds of the population is Catholic, it can be argued that religion is an exogenous factor to the individual's preference regarding immigration.
} 
variable after controlling for the effect of the exogenous variables. Unfortunately, a set of instruments that could help disentangle true exogenous variation in the extended models is not available in the data.

A detailed description of all the variables used in the estimations can be found in the Appendix.

The econometric method used to estimate the regressions will vary depending on the nature of the dependent variable. When this variable is an ordered count with few categories, an ordered probit is estimated. When the dependent variable varies over a larger set of values, a linear model is used. In particular, for the first and third dependent variables an ordered probit is used, while a linear model is applied for the second and fourth dependent variables.

In both cases, the models were estimated with a two-level random intercept, where the first level represents the respondents and the second level represents the geographical provinces in which they live. Furthermore, second-level regressors are included in all models.

\section{Results}

\section{Levels of Immigration}

The first set of results concerns the regressions on whether the respondent believes there are too many immigrants. Table 1 includes these results for both the basic and the extended models. When discussing the impact of the exogenous variables, we will base 
the discussion on the results of the basic model. We do this because the inclusion of potentially endogenous variables in the extended model could bias the estimates of the parameters of the exogenous variables.

The results indicate that males are less likely than females to think that there are too many immigrants. The effect of age, although highly nonlinear, it is relatively flat, except at very old ages, where individuals are less likely to think there are too many immigrants. ${ }^{18}$ More interestingly, less educated individuals and Catholics tend to think there are too many immigrants. Living in a province with a high immigration rate and a high proportion of Moroccans also makes respondents more prone to thinking that immigration should be reduced.

Regarding the impact of the additional set of variables on the extended model, individuals who think wages fall and the poor are particularly affected because of immigration, as well as those who dislike other races, are more likely to think there are too many immigrants, while the opposite occurs for those respondents who prefer cultural diversity, who think immigrants fill vacant jobs, and for those who work with immigrants or have immigrant friends.

\section{TABLE 1 ABOUT HERE}

The more positive attitudes toward immigration among educated respondents support the 'resource' and 'job threat' hypotheses, since more educated individuals are less likely to face competition from immigrants and to be under financial stress. However, it is interesting to note that the 'fiscal burden' hypothesis cannot be confirmed empirically

\footnotetext{
${ }^{18}$ Graphs of the age effects are available from the authors upon request.
} 
since it predicts a more negative attitude among educated individuals bearing the fiscal cost of immigration.

The negative opinion about the current level of immigration from those individuals believing that immigration drops natives’ wages and affects the poor can be explained in terms of the 'pessimism’ hypothesis. Similarly, identitary explanations are supported by the empirical evidence, as shown by the positive relation between cultural and racial tolerance and the acceptance of the current immigration levels and by the negative impact of Moroccan immigration on the acceptance of such levels. The negative attitude of Catholics towards immigrants is also an indication of the importance of identity factors in affecting immigration preferences.

Finally, regarding the contact hypothesis, the results indicate that having contact with immigrants reduces negative attitudes toward them, even if some of this contact is passive, as in the case of work-related contact.

\section{Requirements for Admission}

Tables $2 \mathrm{~A}$ and $2 \mathrm{~B}$ include the results for the estimations on the basic and the extended sets of variables. The estimations were made through random effects linear models.

The results show that for the most part, gender does not affect the requirements conferred upon immigrants, except that males are more likely to consider wealth an important 
factor for accepting immigrants. The desired requirements also increase with the age of the respondent (especially after 40 years of age) and decrease with education. ${ }^{19}$

Married individuals consider family reunification an important criterion for admitting immigrants. On the other hand, Catholics are more restrictionist in general. In order of relevance, they favor giving more importance to admission requirements based on cultural values, education level, family reunification, wealth, and the labor qualifications needed in the country.

Occupational category does not seem to affect the desired admission requirements. However, unemployed individuals are less likely to demand requirements based on cultural values and more likely to caring about requirements based on the labor qualifications needed in the country.

Individuals believing that immigration negatively affects wages are more likely to desire raising admission requirements based on education, wealth, cultural values, and labor qualifications needed. Those individuals believing that the poor are especially hurt by immigration would raise the admission requirements based on the labor needed in the country and on cultural values.

Alternatively, individuals who believe immigrants come to fill vacant jobs are more likely to support family reunification policies, as well as policies aiming to bring immigrants with the qualifications needed in Spain.

\footnotetext{
${ }^{19}$ The degree of the age polynomial is the highest possible such that the lower order terms remain statistically significant.
} 
As is to be expected, individuals who prefer cultural diversity are less restrictionist in general, while those who have negative feelings toward other races are more restrictionist, especially concerning cultural values and wealth.

Finally, individuals who have immigrant friends are less likely to give importance to education and needed labor qualifications as criteria for admitting immigrants.

\section{TABLES 2A AND 2B ABOUT HERE}

As in the previous section, the results from these regressions provide support to the hypotheses proposed in the literature.

\section{Social and Political Rights}

The preference for granting social and political rights to immigrants is relatively flat with respect to age and increasing with respect to the respondent's education level.

Catholics and blue-collar workers are less likely to support extending such rights, as are individuals living in high-immigration provinces. Similarly, respondents who think immigration hurts wages and the poor, and who have negative attitudes toward other races are less likely to support the extension of rights, while the opposite occurs for those who value cultural diversity, who have immigrant friends, and who think that immigrants fill vacant jobs.

\section{TABLE 3 ABOUT HERE}




\section{Economic Benefits}

Regarding attitudes about granting health and education to immigrants (and their children), age and gender seem to have no role, while only the most educated individuals support increasing such benefits. On the other hand, Catholics, blue-collar workers, and respondents in provinces with a high immigration rate are less likely to support offering such benefits.

What these results indicate is that respondents at the bottom of the income distribution are less likely to support extending economic benefits to immigrants, probably out of fear of competition in the use of such public goods. The 'fiscal burden' hypothesis, wherein rich taxpayers would oppose increasing costly public services to immigrants, does not appear to hold for the Spanish case.

Individuals thinking that immigration hurts the poor would like to reduce the welfare benefits granted to immigrants, while the opposite occurs for those thinking that immigrants come to fill vacant jobs. Finally, individuals with negative attitudes toward other races also oppose extending benefits.

\section{TABLE 4 ABOUT HERE}

It is interesting to note that both here and in the previous table, including variables capturing the preference for cultural diversity, as well as other subjective opinions on immigration, renders the impact of the education dummies insignificant. This could reflect that part of the effect of education in the basic model is capturing preferences about diversity that more educated natives have. 


\section{Information and Preferences}

As mentioned above, how much an individual knows (or thinks he/she knows) about immigration shapes his/her attitudes toward immigrants.

In our estimation of the extended model, we included a variable capturing the perceived fraction of the population of foreign origin, measured in excess with respect to the actual number. In other words, a positive value of the variable indicates an overestimation of the rate of immigrants living in Spain, while a negative value indicates an underestimation.

Since more than $30 \%$ of the interviewees did not respond to this question, a separate set of estimations for each model was performed including this variable and all of the possible controls. By conducting these separate estimations, we avoid reducing the number of observations used to estimate the parameters of other variables.

The parameter for the variable measuring the perceived fraction of immigrants in the population is included in Table 5. In this table, each line corresponds to the parameter of interest in a different model. In all cases, a full set of controls were included, but the results are not presented for the sake of compactness. ${ }^{20}$

\section{TABLE 5 ABOUT HERE}

Table 5 shows that individuals overestimating the fraction of immigrants in the country want to reduce the levels of immigrants accepted. In particular, they favor increasing the weight given to skills and cultural values when deciding who is admitted to Spain, and

\footnotetext{
${ }^{20}$ The full set of results is available from the authors.
} 
they also favor reducing the benefits and rights granted to immigrants already living in the country.

As before, this variable could potentially be endogenous to the question asked. In other words, it could be that wanting stricter immigration policies makes someone think that there are too many immigrants. However, we believe that even if strict causality cannot be claimed, the negative association between the subjective estimates of the number of immigrants and the attitudes toward them supports the hypotheses posited in the literature regarding the relation between perceptions, information and attitudes.

\section{Conclusions}

The present body of research examined the attitudes of native Spaniards toward immigrants and the reasons underlying such preferences.

This paper brings new evidence regarding public opinion on immigration by studying the Spanish case, which has not received the attention it deserves in the literature. It also analyzes the issue from a richer perspective than previous studies by inquiring into not only the respondents' opinions about current immigration levels, but also their preferences on the policies for accepting immigrants in the country and the types of rights and benefits to be granted to foreigners living in Spain.

In general, we find a preference for reducing the current levels of immigration in Spain. The admission criteria that have the most support among the population are the skills of the immigrants and the match between their labor qualifications and the qualifications 
needed in the Spanish labor market. However, it is important to emphasize that in spite of this, respondents tend to favor expanding the rights and benefits granted to immigrants.

Our results also support many of the hypotheses proposed in the literature on public opinion and immigration.

First, we find that skilled natives tend to have a more positive attitude toward immigration in the sense that they are more likely to tolerate higher levels of immigration, require less demanding admission criteria, and be willing to grant higher levels of benefits and rights to immigrants. This is understandable since more educated natives face less competition from immigrants in the labor market and in their use of public services. It could also reflect that such individuals have a higher preference for the cultural diversity brought about by immigration.

In any case, it is interesting to note that in Spain, unlike in the United States, richer individuals (i.e., more skilled ones) have a more positive attitude toward immigration, in spite of the potential fiscal burden on them that it implies.

We find support for the 'pessimism hypothesis' since respondents who believe that immigration drops natives' wages and negatively affects the poor are more prone to oppose immigration and desire reducing the number of benefits and rights granted to immigrants.

Regarding identity-related factors, we found more negative attitudes among those individuals who reject other races, while the opposite occurred for those valuing cultural diversity. A particularly interesting result was the restrictionist attitude of Christians, who 
in general want fewer immigrants, more barriers to entry and fewer benefits and rights given to foreigners living in Spain. Furthermore, the evidence shows that the admission criteria Christians give more importance to revolve around cultural factors like religion, language and race.

Respondents living in provinces with high immigration rates are more likely to want the immigration levels reduced and the rights and benefits granted to foreigners limited.

Our study also addressed whether there was a particularly negative attitude toward migrants from Arab countries, in particular toward Moroccans. In this regard we find that respondents living in provinces with a high proportion of Moroccans are more prone to desire lower levels of immigration. However, this characteristic plays virtually no role in determining the type of migration policy or the number of benefits and rights to award to immigrants. This mild rejection of Moroccan migration is worth noting given that negative attitudes toward Arabs spiked after the terrorist attacks of March 11, 2004.

We found empirical support for the 'contact' hypothesis. In particular, the results indicate that having contact with immigrants reduces negative attitudes toward them, especially when this contact is active, as in the case of friendship. Nevertheless, these results should be taken with caution because of the potential endogeneity between having an immigrant friend and the general attitude toward immigrants.

Finally, we find that individuals who overestimate the number of immigrants living in Spain are more prone to have negative attitudes toward them. While we make no claim of 
causality here, the results indicate that informing individuals about the actual facts of immigration might modify their perceptions on the topic.

The direction that Spanish immigration policy will follow in the years to come will be guided by the preferences of natives and the responsiveness of policymakers to such preferences. If politicians tend to endorse these preferences, then we should expect the implementation of more restrictionist policies with a stronger emphasis on the skills of the immigrants, although not necessarily with a reduction in the benefits granted to them. These pressures will be stronger at the local level in provinces with high immigration rates. 


\section{Bibliography}

Allport, G. 1954 The Nature of Prejudice. Cambridge, MA: Addison-Wesley.

Axelrod, R. 1984 The Evolution of Cooperation. New York: Basic Books.

Boix, C., and D. Posner 1996 "Making Social Capital Work: A Review of Robert Putnam's 'Making Democracy Work: Civic Traditions in Modern Italy'” Working Paper, Weatherhead Center for International Affairs, Harvard University.

Borjas, G., and L. Hilton 1996 "Immigration and the Welfare State: Immigrant Participation in Means-Tested Entitlement Programs” Quarterly Journal of Economics Vol. 118(2): 575-604.

Borjas, G. 1999 Heaven's Door: Immigration Policy and the American Economy. Princeton, NJ: Princeton University Press.

Brewer, M. 1999 “The Psychology of Prejudice: Ingroup Love or Outgroup Hate?” Journal of Social Issues 55(3):429-44.

Brewer, M. 2001 "Ingroup Identification and Intergroup Conflict: When Does Ingroup Love Become Outgroup Hate?” In Social Identity, Intergroup Conflict and Conflict Reduction. Ed. Richard D. Ashmore, Lee Jussim, and David Wilder. New York: Oxford University Press.

Brown, R. 2000 "Social Identity Theory: Past Achievements, Current Problems and Future Challenges” European Journal of Social Psychology 30:745-78.

Burns, P., and J. Gimpel 2000 "Economic Insecurity, Prejudicial Stereotypes, and Public Opinion on Immigration Policy” Political Science Quarterly 115(2):201-225.

Cachón, L. (2000) Prevenir el Racismo en el Trabajo en España. Madrid: Observatorio Permanente de la Inmigración.

Campbell, Donald T. 1958 "Common Fate, Similarity, and Other Indices of the Status of Aggregates of Persons as Social Entities.” Behavioral Science 3(1):14-25.

Centro de Investigaciones Sociológicas 2005 “Barómetro de Noviembre” Estudio CIS 2.625. Documentación Técnica.

Christofides, L. N., S. Clerides, C. Hadjiyiannis, and M. Michael 2007 "The Impact of Foreign Workers on the Labour Market of Cyprus." Cyprus Economic Policy Review, 1(2):37-49.

Citrin, J., B. Reingold, and D. Green 1990 “American Identity and the Politics of Ethnic Change” Journal of Politics 52:1124-54. 
Citrin, J., D. Green, Ch. Muste, and C. Wong 1997 "Public Opinion Toward Immigration Reform: The Role of Economic Motivations” Journal of Politics 59:858-81.

Citrin, J. and J. Sides 2006 “European immigration in the people's court.” In Immigration and the transformation of Europe. Eds. C. Parsons, and T. Smeeding, Cambridge University Press.

Citrin, J., and J. Sides 2007 "European Opinion About Immigration: The Role of Identities, Interests and Information” British Journal of Political Science 37:477504.

Corkill, D. 2001 "Economic migrants and the labour market in Spain and Portugal" Ethnic and Racial Studies 24(5):828-844.

Christin, T., and A. Treschel 2002 "Joining the EU? Explaining Public Opinion in Switzerland” European Union Politics 3(4):415-43.

Dolado J.J. 2002 “Los Nuevos Fenómenos Migratorios: Retos y Políticas.” In Las nuevas Fronteras de la Política Económica en España, Ed. T. García-Milá, CREI, Universidad Pompeu Fabra and Generalitat de Catalunya.

Dustman, C., and I. Preston 2000 "Racial and Economic Factors in Attitudes to Immigration” IZA Discussion Paper, Nº 120.

Eliofotou, P. S. 2008 "Cyprus: immigration, wage indexation and the adjustment in EMU.” ECFIN Country Focus, 5(10), Economic Analysis from the European Comission's Directorate-General for Economic and financial Affairs.

El País. 2008, April 14 ${ }^{\text {th }}$.

Escandell, X., and A. Ceobanu 2009 "When contact with immigrants matters: threat, interethnic attitudes and foreigner exclusionism in Spain's Comunidades Autonomas” Ethnic and Racial Studies 32(1):44-69.

Espenshade, T., and C. Calhoun 1993 "An Analysis of Public Opinion toward Undocumented Immigration” Population Research and Policy Review 12:189224.

Espenshade, T. and K. Hempstead 1996 “Contemporary American Attitudes Toward U.S. Immigration.” International Migration Review 30(2):535-570.

Facchini, G., and A. Mayda 2006 "Individual Attitudes Towards Immigrants: WelfareState Determinants Across Countries" CEPR Discussion Paper No. 5702.

Fix, M., and J. Passel 1994 “Myths About Immigrants” Foreign Policy 95:151-60. 
Gurr, T. R. 1970 Why men rebel. Princeton, NJ: Princeton University Press.

Hanson, G. 2005 Why Does Immigration Divide America? Public Finance and Political Opposition to Open Borders. Washington, DC: Institute for International Economics.

Hanson, G., K. Scheve, and M. Slaughter "Individual Preferences Over High-Skilled Immigration in the United States." In Skilled Immigration Today: Problems, Prospects, and Policies. Eds. J. Bhagwati and G. Hanson, Oxford University Press, forthcoming.

Hechter, M. 1975 Internal Colonialism. Berkeley, Calif.: University of California Press.

Hoskin, M. 1991 New Immigrants and Democratic Society. New York: Praeger.

Izquierdo, M., J. Jimeno, and J. Rojas 2007 "On the Aggregate Effects of Immigration in Spain” Banco de España. Documentos de Trabajo. Nº $^{\circ} 14$.

Karapin, R. 1999 "The Politics of Immigration Control in Britain and Germany: Subnational Politicians and Social Movements" Comparative Politics 31(4):423444.

Luedtke, A. 2005 "European Integration, Public Opinion and Immigration Policy: Testing the Impact of National Identity” European Union Politics 6:83-112.

Masson, C., and M. Verkuyten 1993 "Prejudice, Ethnic Identity, Contact, and Ethnic Group Preferences among Dutch Young Adolescents.” Journal of Applied Social Psychology 23:156-68.

Mayda, A. 2006 "Who is Against Immigration? A Cross-Country Investigation of Individual Attitudes towards Immigrants" Review of Economics and Statistics 88(3):510-530.

McLaren, L. 2003 “Anti-Immigrant Prejudice in Europe: Contact, Threat Perception, and Preferences for the Exclusion of Migrants” Social Forces 81(3):909-936.

Mummendey, A., T. Kessler, A. Klink, and R. Mielke 1999 "Strategies to Cope With Negative Social Identity: Predictions by Social Identity Theory and Relative Deprivation Theory" Journal of Personality and Social Psychology 76(2):229245.

Nadeau, R., R. Niemi, and J. Levine 1993 "Innumeracy About Minority Populations” Public Opinion Quarterly 57:332-347.

Olzak, S. 1992 The Dynamics of Ethnic Competition and Conflict. Stanford: Stanford University Press. 
O’Rourke, K., and R. Sinnott 2006 “The Determinants of Individual Attitudes Towards Immigration” European Journal of Political Economy 22:838-861.

Ortuño Aix., J.M. 2006 "Securization and Religious Divides in Europe Muslims in Western Europe After 9/11: Why the term Islamophobia is more a predicament than an explanation” http://www.libertysecurity.org/article1167.html

Pettigrew, T. 1998 “Intergroup Contact Theory” Annual Review of Psychology 49:65-85.

Putnam, R. D. 1993 Making Democracy Work. NJ: Princeton University Press.

Runciman, W. G. 1966 Relative deprivation and social justice: A study of attitudes to social inequality in twentieth-century England. Berkeley: University of California Press.

Sides, J., and J. Citrin 2007 "How Large the Huddled Masses? The Causes and Consequences of Public Misperceptions about Immigrant Populations" Paper presented at the Annual 2007 Meeting of the Midwest Political Science Association, Chicago, IL.

Sigelman, L. and R. Niemi 2001 "Innumeracy About Minority Populations: AfricanAmericans and Whites Compared” Public Opinion Quarterly 65: 86-94.

Smith, A. D. 2001 Nationalism: Theory, Ideology, History. Cambridge: Polity.

Sniderman, P., L. Hagendoorn, and M. Prior 2004 "Predisposing Factors and Situational Triggers: Exclusionary Reactions to Immigrant Minorities.” American Political Science Review 98(1):35-49.

Solé, C., and S. Parella 2003 "The labour market and racial discrimination in Spain" Journal of Ethnic and Migration Studies 29(1):121-140.

Tajfel, H. 1981 Human Groups and Social Categories: Studies in Social Psychology. Cambridge: Cambridge University Press.

Theiss-Morse, E. 2003 "Characterizations and Consequences: How Americans Envision the American People" Paper presented at the 2003 Annual Meeting of the Midwest Political Science Associacition, Chicago, IL.

Wagner, U., R. Van Dick, T.F. Pettigrew, and O. Christ 2003 "Ethnic Prejudice in East and West Germany: The Explanatory Power of Intergroup Contact" Group Processes \& Intergroup Relations 6(1):22-36.

Williams, R. 1947 The Reduction of Intergroup Tensions. New York: Social Science Research Council. 


\section{Appendix}

This appendix includes a detailed description of the variables used in the estimations.

\section{Dependent Variables}

1) "The number of people coming from another country... Do you think it is not a lot, a lot but not too many, or too many?”

2) "How important should each of the following aspects be in order to allow a foreigner to live here?”

a. Education: Being well educated,

b. Family: Having family members already living in Spain,

c. Culture: An average of being a Spanish or regional language speaker, being from a Christian country, or being of white race,

d. Wealth: being wealthy,

e. Labor Requirements: Having a labor qualification needed in Spain (not necessarily highly skilled).

The response options ranged from 0 to 10 according to the importance attached to each option.

3) Social and political rights.

The variable counts the number of affirmative answers to the following questions:

"Do you think foreign immigrants should be given facilities to...:

a) bring their family with them?”

b) have equal conditions with natives in the workplace?”

c) freely practice their religion?”

d) form associations to defend their rights?"

"Do you think a foreigner living for a long time in Spain should be allowed to...:

e) vote in municipal elections?”

f) vote in general elections?”

g) join political parties or unions?”

h) eventually apply for Spanish citizenship?”

4) Economic Rights/Benefits

The variable counts the number of affirmative answers to the following questions:

"Do you think foreign immigrants should be given facilities to...:

a) access the public education system (for them or their children)?”

b) freely access medical services?”

\section{Independent Variables}

Male - Dummy for male respondents

Age - Age of the respondent 


\section{Schooling}

Illiterate and Elementary Incomplete - (Omitted category)

Elementary - Completed Elementary Schooling (6 years)

Basic Secondary - Basic Secondary Education (4 years) or Medium Level Professional Training

Higher Secondary - Higher Secondary Education (2 years) or Higher Level Professional Training

Technical - Technical Degree

Superior - Bachelor's Degree or higher

Married - Dummy for married respondent

Catholic -Dummy for Catholic respondent

White-Collar (Omitted category)

Blue-Collar - Dummy for Blue-Collar Worker

Service - Dummy for worker in service occupation

Unemployed - Dummy for unemployed respondent

Province Immig. Rate - Immigration rate at the province level

\% Moroccan Immigrants - Percent of Moroccans among the immigrant population at the province level

GDP Per Capita (000s Euros)- Per Capita GDP in (000s Euros) at the Autonomous Community level

"Wages fall..." - Answer to question:

"In general, wages fall as a consequence of people coming to Spain to live and work."

The response variable ranges from 1 to 5 according to degree of agreement.

"Impact on Poor..." - Answer to question:

"In general, the coming of people to Spain to live and work more severely affects the economic outlook of poor Spaniards."

The response variable ranges from 1 to 5 according to degree of agreement.

"Labor needed..."- Answer to question:

"In general, people coming to Spain to live and work allow the filling of vacant jobs for which there is insufficient workforce."

The response variable ranges from 1 to 5 according to degree of agreement.

Preference for Diversity - Answer to question:

"If you had to choose a place to live, where would you prefer to do so?

1) In a place where almost nobody was of an ethnic group or race different from the majority of Spaniards."

2) In a place where some people were of an ethnic group or race different from the majority of Spaniards."

3) I am indifferent.” 
4) In a place where most of the people were of an ethnic group or race different from the majority of Spaniards."

The values of the response variable follow the ranking in the previous options.

Rejects other races - Average of the answers to the two following questions:

"Considering the foreigners who come to live in Spain and who are from a different race or ethnic group than the majority of Spaniards...

a) How much would you care if one of these persons was your boss?”

b) How much would you care if one of these persons married a close relative of yours?”

The responses range from 0 to 10 according to degree of importance.

Contact Variables - Answers to the questions:

"Have you ever had contact with immigrants in Spain through...

a) Work?”

b) Neighborhood?"

c) Friendship?"

The values are dichotomous with 1 indicating 'yes' and 0 'no'.

Perceived No. of Immigrants - Answer to question:

"Of every 100 persons living in Spain, how many do you think were born abroad?"

The answer is de-meaned with respect to the actual level, i.e., $11 \%$. Hence, positive values indicate an overestimation of the percentage of foreigners, and a negative value reflects an underestimation of this fraction.

Table A-1 presents descriptive statistics for the variables used in the study.

TABLE A-1 ABOUT HERE

Table A-2 shows the correlation between the dependent variables in the study.

TABLE A-2 ABOUT HERE 
Figures and Tables

Figure 1
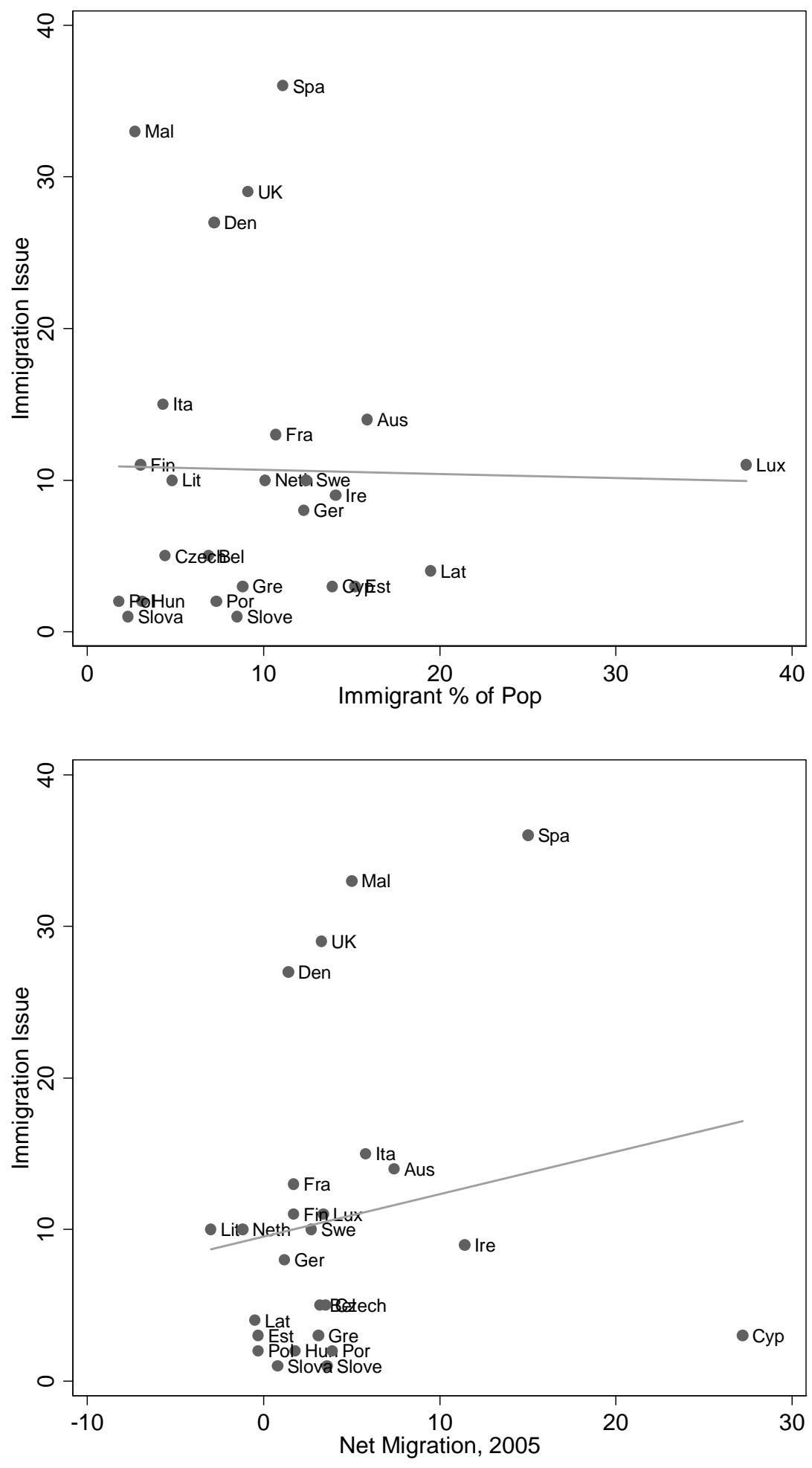

Own elaboration. Sources: EUROSTAT, Eurobarometer 64.2 (2005) and UN Publications Sales No. E.06.XIII.6 
Figure 2

Number of Immigrants

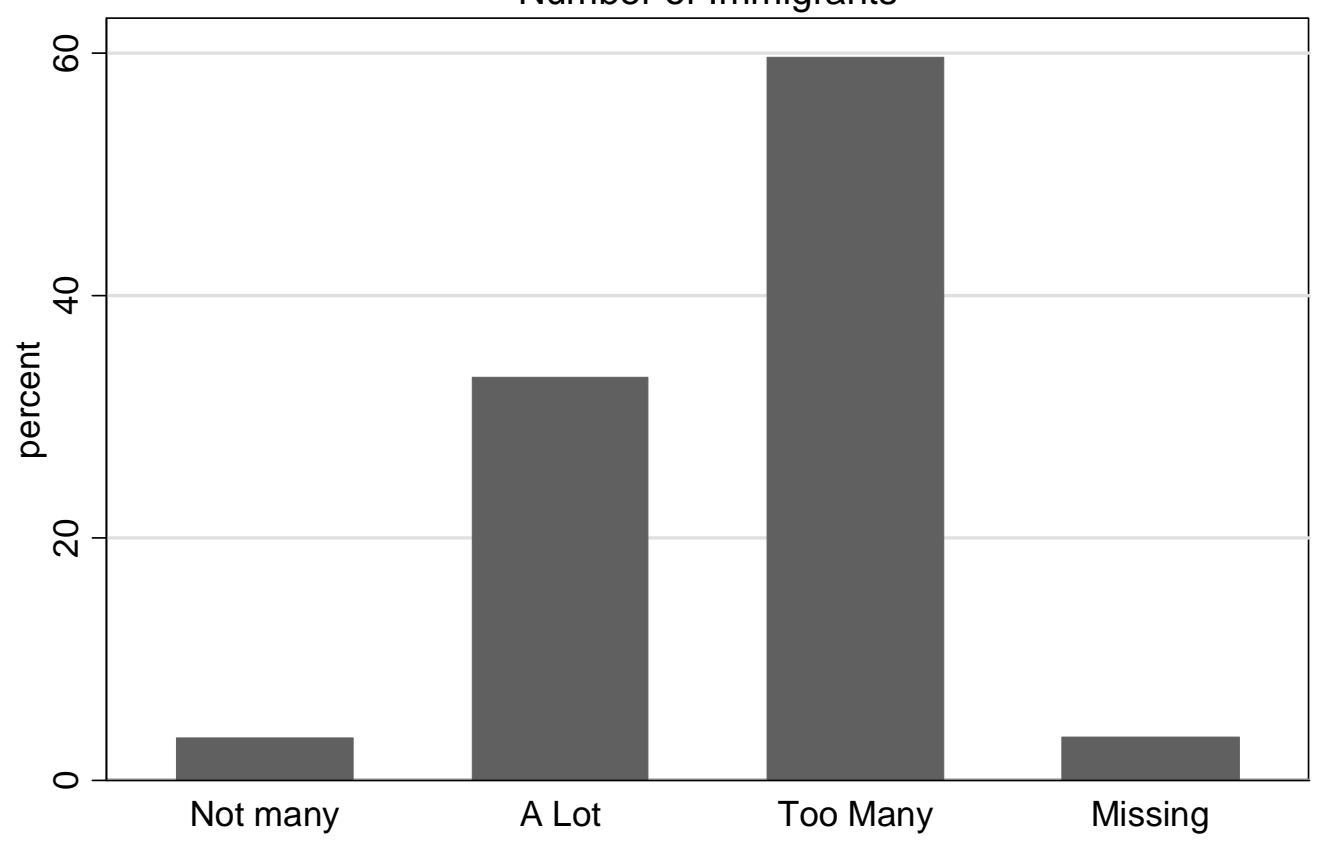

Figure 3

Requirements for Accepting Immigrants
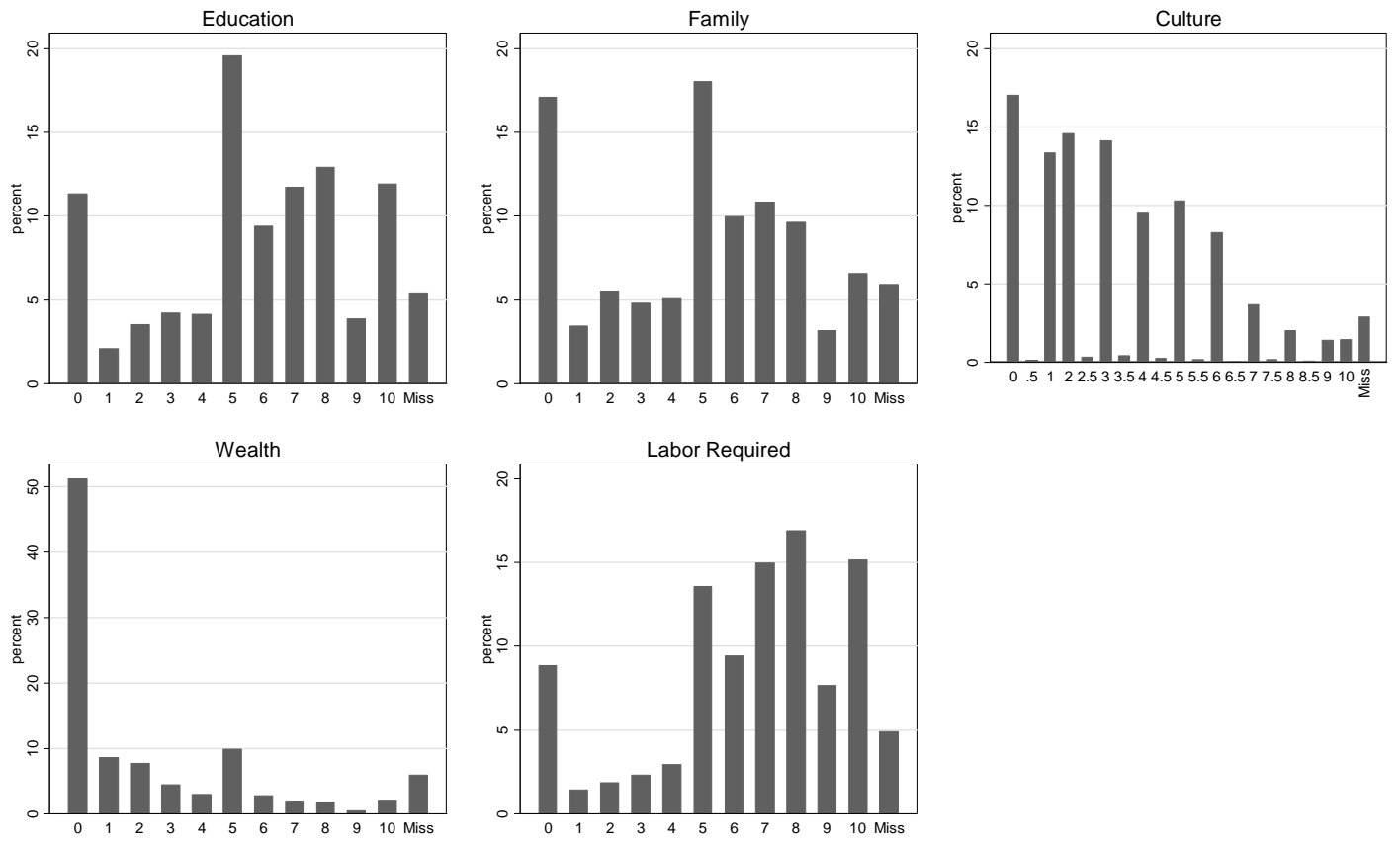

0-Not Important, 10-Very Important 
Figure 4

Rights and Benefits for Immigrants
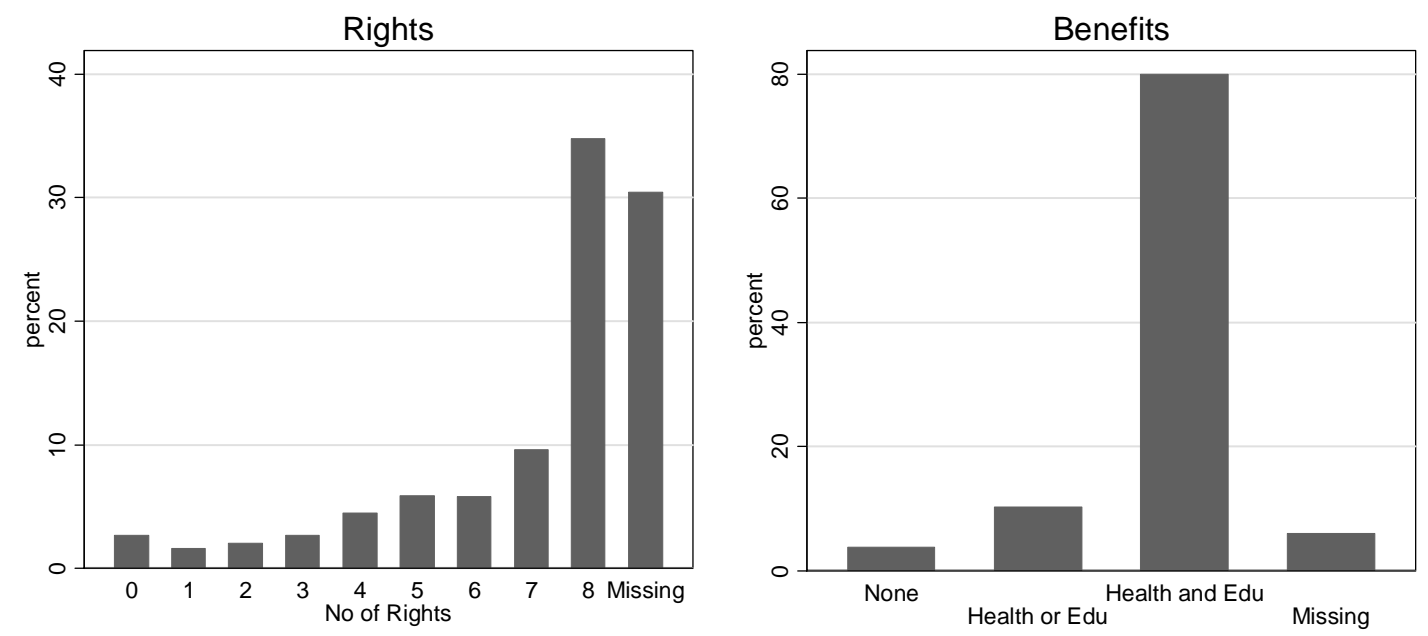
Table 1

\begin{tabular}{|c|c|c|c|c|c|c|}
\hline \multirow{3}{*}{$\frac{\text { Variable }}{\text { Male }}$} & \multicolumn{6}{|c|}{$\begin{array}{l}\text { Dep. Var: Too Many Inmigrants } \\
\text { Multilevel Ordered Probit }\end{array}$} \\
\hline & Coef. & Std. Error & & Coef. & Std. Error & \\
\hline & -0.18 & $(0.09)$ & * & -0.08 & $(0.11)$ & \\
\hline Age & 0.44 & $(0.18)$ & $* *$ & 0.51 & $(0.18)$ & $* * *$ \\
\hline$(\text { Age } / 10)^{2}$ & -1.55 & $(0.60)$ & $* * *$ & -1.85 & $(0.61)$ & $* * *$ \\
\hline$(\text { Age } / 10)^{3}$ & 0.22 & $(0.08)$ & $* * *$ & 0.27 & $(0.08)$ & $* * *$ \\
\hline$(\text { Age/10) })^{4}$ & -0.01 & $(0.00)$ & $* * *$ & -0.01 & $(0.00)$ & $* * *$ \\
\hline \multicolumn{7}{|l|}{ Schooling } \\
\hline Elementary Completed & -0.42 & $(0.22)$ & * & -0.19 & $(0.29)$ & \\
\hline Basic Secondary & -0.34 & $(0.24)$ & & -0.04 & $(0.31)$ & \\
\hline Higher Secondary & -0.80 & $(0.25)$ & $* * *$ & -0.49 & $(0.32)$ & \\
\hline Technical & -1.53 & $(0.28)$ & $* * *$ & -1.12 & $(0.35)$ & $* * *$ \\
\hline Superior & -1.55 & $(0.28)$ & $* * *$ & -1.10 & $(0.35)$ & $* * *$ \\
\hline Married & 0.11 & $(0.11)$ & & 0.17 & $(0.13)$ & \\
\hline Catholic & 1.05 & $(0.12)$ & $* * *$ & 0.78 & $(0.14)$ & $* * *$ \\
\hline Blue-Collar Worker & 0.12 & $(0.15)$ & & -0.16 & $(0.18)$ & \\
\hline Service Worker & 0.05 & $(0.14)$ & & -0.04 & $(0.16)$ & \\
\hline Unemployed & 0.12 & $(0.16)$ & & 0.17 & $(0.18)$ & \\
\hline Province Immig. Rate & 0.04 & $(0.02)$ & ** & 0.06 & $(0.02)$ & ** \\
\hline \% Moroccan Immigrants & 0.03 & $(0.01)$ & $* * *$ & 0.02 & $(0.01)$ & ** \\
\hline GDP Per Capita (000s Euros) & -0.01 & $(0.02)$ & & -0.02 & $(0.02)$ & \\
\hline Regionalistic Community & -0.17 & $(0.17)$ & & -0.27 & $(0.18)$ & \\
\hline "Wages fall..." & & & & 0.16 & $(0.05)$ & *** \\
\hline "Impact on Poor..." & & & & 0.30 & $(0.05)$ & $* * *$ \\
\hline "Labor needed..." & & & & -0.14 & $(0.05)$ & $* * *$ \\
\hline Preference for Diversity & & & & -0.28 & $(0.06)$ & $* * *$ \\
\hline Rejects other Races & & & & 0.12 & $(0.02)$ & *** \\
\hline Work Contact & & & & -0.23 & $(0.12)$ & * \\
\hline Neighbor Contact & & & & -0.11 & $(0.12)$ & \\
\hline Frienship Contact & & & & -0.31 & $(0.12)$ & ** \\
\hline Cut 1 & 1.40 & (1.98) & & 1.88 & $(2.06)$ & \\
\hline Cut 2 & 4.54 & $(1.98)$ & $* *$ & 5.26 & $(2.06)$ & ** \\
\hline Variance Province R.Effect & & 0.17 & & & 0.1 & \\
\hline Log-Likelihood & & -1650.4 & & & -1233.1 & \\
\hline Number of Observations & & 2346 & & & 190 & \\
\hline Number of Provinces & & 47 & & & 4 & \\
\hline
\end{tabular}

1/Dep Var: 1-There are not many inmigrants, 2-There are a lot but not too many inmigrants, or

3-There are too many inmigrants

$* * *, * *, * \mathrm{H} 0: \beta=0$ rejected at $99,95,90 \%$ of significance 
Table 2A

Dep. Var: Requirements for Accepting Inmigrants ${ }^{1}$

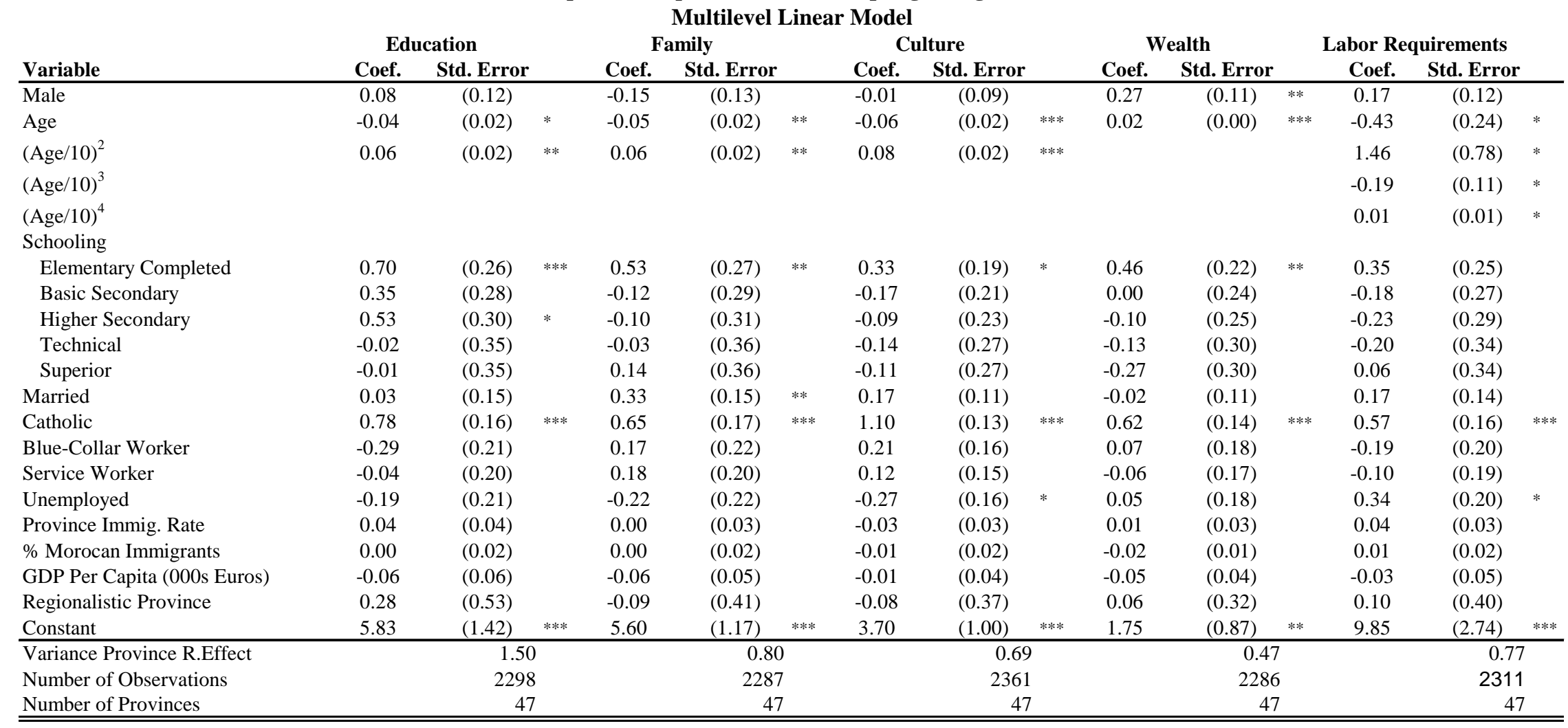

1/Dep Var. Ranges from 0 to 10 , where 0 denotes 'not important', and 10 'very important'

$* * *, * *, * \mathrm{H0}: \beta=0$ rejected at $99,95,90 \%$ of significance 
Table 2B

Dep. Var: Requirements for Accepting Inmigrants ${ }^{1}$

Multilevel Linear Model

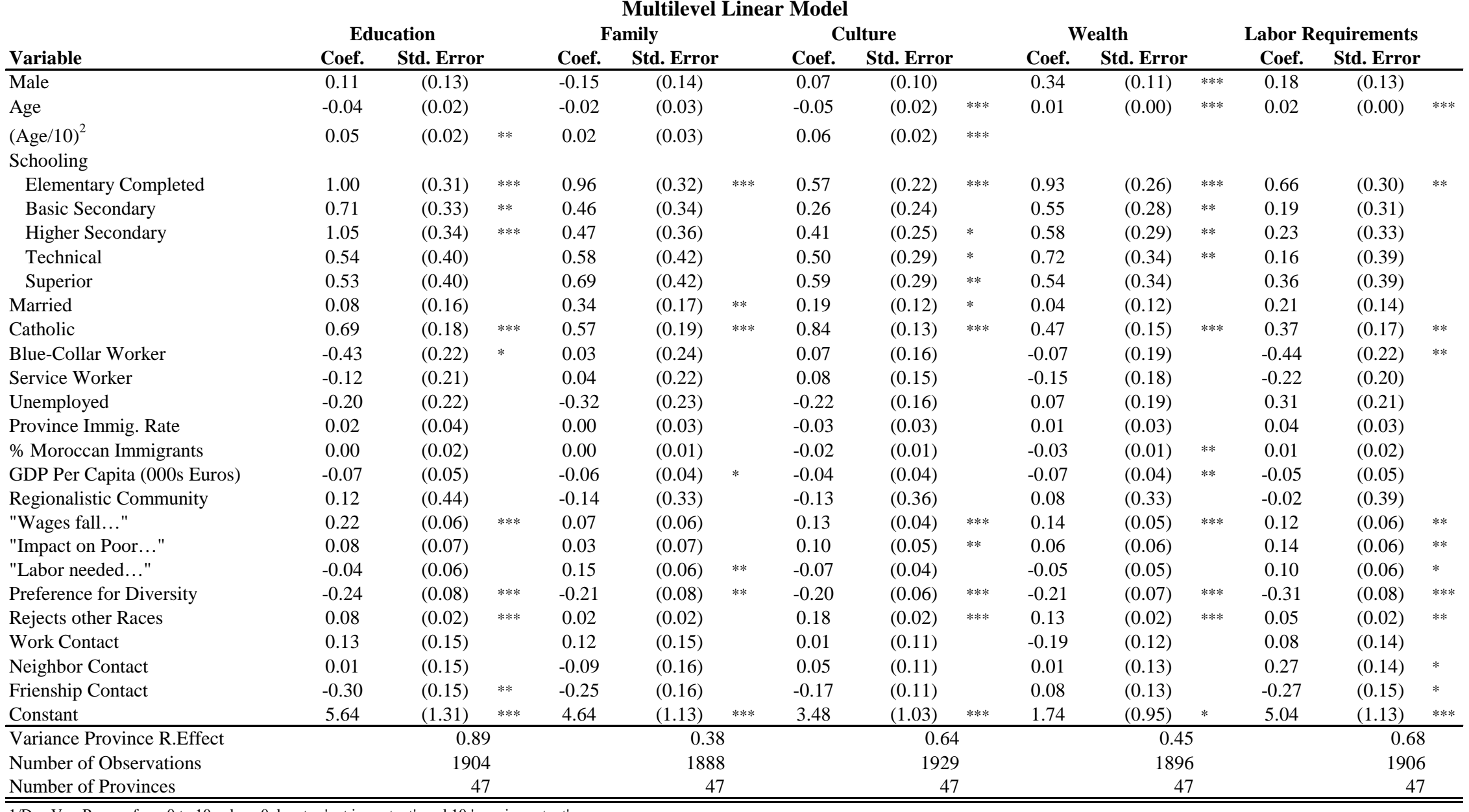

1/Dep Var. Ranges from 0 to 10, where 0 denotes 'not important', and 10 'very important'

$* * *, * *, * H 0: \beta=0$ rejected at $99,95,90 \%$ of significance 
Table 3

Dep. Var: Number of Social and Political Rights ${ }^{1}$

Multilevel Linear Model

\begin{tabular}{|c|c|c|c|c|c|c|}
\hline Variable & Coef. & Std. Error & & Coef. & Std. Error & \\
\hline Male & -0.10 & $(0.11)$ & & -0.18 & $(0.10)$ & * \\
\hline Age & 0.41 & $(0.21)$ & * & 0.15 & $(0.06)$ & $* *$ \\
\hline$(\text { Age } / 10)^{2}$ & -1.28 & $(0.69)$ & * & -0.30 & $(0.13)$ & $* *$ \\
\hline$(\text { Age } / 10)^{3}$ & 0.17 & $(0.09)$ & * & 0.02 & $(0.01)$ & $* *$ \\
\hline$(\text { Age/10) })^{4}$ & -0.01 & $(0.00)$ & * & & & \\
\hline Schooling & & & & & & \\
\hline Elementary Completed & 0.56 & $(0.24)$ & ** & 0.16 & $(0.24)$ & \\
\hline Basic Secondary & 0.51 & $(0.26)$ & ** & -0.13 & $(0.25)$ & \\
\hline Higher Secondary & 0.84 & $(0.27)$ & $* * *$ & 0.03 & $(0.26)$ & \\
\hline Technical & 0.78 & $(0.32)$ & ** & -0.27 & $(0.31)$ & \\
\hline Superior & 1.00 & $(0.31)$ & $* * *$ & -0.04 & $(0.30)$ & \\
\hline Married & -0.17 & $(0.13)$ & & -0.12 & $(0.12)$ & \\
\hline Catholic & -0.42 & $(0.14)$ & $* * *$ & -0.02 & $(0.13)$ & \\
\hline Blue-Collar Worker & -0.37 & $(0.18)$ & $* *$ & -0.31 & $(0.16)$ & * \\
\hline Service Worker & -0.08 & $(0.17)$ & & -0.16 & $(0.15)$ & \\
\hline Unemployed & -0.28 & $(0.18)$ & & -0.25 & $(0.16)$ & \\
\hline Province Immig. Rate & -0.06 & $(0.03)$ & $* *$ & -0.06 & $(0.03)$ & ** \\
\hline \% Morocan Immigrants & 0.01 & $(0.02)$ & & 0.03 & $(0.01)$ & $* *$ \\
\hline GDP Per Capita (000s Euros) & 0.02 & $(0.04)$ & & 0.049 & $(0.04)$ & \\
\hline Regionalistic Province & -0.04 & $(0.36)$ & & 0.03 & $(0.31)$ & \\
\hline "Wages fall..." & & & & -0.21 & $(0.04)$ & *** \\
\hline "Impact on Poor..." & & & & -0.08 & $(0.05)$ & * \\
\hline "Labor needed..." & & & & 0.29 & $(0.05)$ & $* * *$ \\
\hline Preference for Diversity & & & & 0.50 & $(0.06)$ & $* * *$ \\
\hline Rejects other Races & & & & -0.21 & $(0.02)$ & $* * *$ \\
\hline Work Contact & & & & -0.11 & $(0.11)$ & \\
\hline Neighbor Contact & & & & -0.02 & $(0.11)$ & \\
\hline Frienship Contact & & & & 0.31 & $(0.11)$ & $* * *$ \\
\hline Constant & 1.65 & $(2.44)$ & & 2.73 & $(1.21)$ & ** \\
\hline Variance Province R.Effect & \multirow{2}{*}{\multicolumn{4}{|c|}{$\begin{array}{r}0.62 \\
1688\end{array}$}} & \multicolumn{2}{|l|}{0.42} \\
\hline Number of Observations & & & & & \multicolumn{2}{|c|}{1440} \\
\hline Number of Provinces & \multicolumn{4}{|c|}{$\begin{array}{r}1688 \\
46\end{array}$} & \multicolumn{2}{|c|}{45} \\
\hline
\end{tabular}

1/Dep Var. ranges between 0 and 8 depending on number of social and political rights that would be granted $* * *, * *, * \mathrm{H} 0: \beta=0$ rejected at $99,95,90 \%$ of significance 
Table 4

Dep. Var: Number of Economic Benefits ${ }^{1}$ Multilevel Ordered Probit

\begin{tabular}{|c|c|c|c|c|c|c|}
\hline Variable & Coef. & Std. Error & & Coef. & Std. Erro1 & \\
\hline$\overline{\text { Male }}$ & 0.15 & $(0.13)$ & & 0.21 & $(0.15)$ & \\
\hline Age & 0.01 & $(0.00)$ & & 0.01 & $(0.006)$ & $*$ \\
\hline \multicolumn{7}{|l|}{ Schooling } \\
\hline Elementary Completed & 0.15 & $(0.25)$ & & 0.12 & $(0.32)$ & \\
\hline Basic Secondary & 0.24 & $(0.27)$ & & 0.04 & $(0.34)$ & \\
\hline Higher Secondary & 0.38 & $(0.29)$ & & -0.05 & $(0.36)$ & \\
\hline Technical & 0.14 & $(0.35)$ & & -0.24 & $(0.44)$ & \\
\hline Superior & 0.74 & $(0.39)$ & * & 0.17 & $(0.46)$ & \\
\hline Married & -0.22 & $(0.14)$ & & -0.31 & $(0.16)$ & * \\
\hline Catholic & -0.36 & $(0.18)$ & ** & -0.10 & $(0.21)$ & \\
\hline Blue-Collar Worker & -0.45 & $(0.23)$ & * & -0.38 & $(0.27)$ & \\
\hline Service Worker & -0.16 & $(0.22)$ & & -0.12 & $(0.26)$ & \\
\hline Unemployed & -0.15 & $(0.21)$ & & -0.15 & $(0.25)$ & \\
\hline Province Immig. Rate & -0.07 & $(0.01)$ & $* * *$ & -0.05 & $(0.03)$ & * \\
\hline \% Morocan Immigrants & 0.01 & $(0.02)$ & & 0.05 & $(0.02)$ & $* *$ \\
\hline GDP Per Capita (000s Euros) & -0.02 & $(0.02)$ & & 0.01 & $(0.03)$ & \\
\hline Regionalistic Province & 0.27 & $(0.25)$ & & 0.58 & $(0.33)$ & * \\
\hline "Wages fall..." & & & & -0.04 & $(0.06)$ & \\
\hline "Impact on Poor..." & & & & -0.40 & $(0.09)$ & $* * *$ \\
\hline "Labor needed..." & & & & 0.31 & $(0.06)$ & $* * *$ \\
\hline Preference for Diversity & & & & 0.11 & $(0.09)$ & \\
\hline Rejects other Races & & & & -0.18 & $(0.02)$ & $* * *$ \\
\hline Work Contact & & & & -0.09 & $(0.16)$ & \\
\hline Neighbor Contact & & & & 0.15 & $(0.17)$ & \\
\hline Frienship Contact & & & & 0.23 & $(0.17)$ & \\
\hline Cut 1 & -4.51 & $(0.77)$ & $* * *$ & -3.96 & $(1.00)$ & $* * *$ \\
\hline Cut 2 & -2.99 & $(0.76)$ & $* * *$ & -2.22 & $(1.00)$ & $* *$ \\
\hline Variance Province R.Effect & \multicolumn{4}{|c|}{0.88} & \multicolumn{2}{|c|}{0.51} \\
\hline Log-Likelihood & \multicolumn{4}{|c|}{-1097.37} & \multicolumn{2}{|c|}{-825.28} \\
\hline Number of Observations & \multicolumn{4}{|c|}{2283} & \multicolumn{2}{|c|}{1864} \\
\hline Number of Provinces & \multicolumn{4}{|c|}{47} & \multicolumn{2}{|c|}{47} \\
\hline
\end{tabular}

1/Dep Var: Number of Benefits, 0- No benefits 1-Either health or education benefits, but not both,

2-Both Health and Education benefits

$* * *, * *, * \mathrm{H0}: \beta=0$ rejected at $99,95,90 \%$ of significance 
Table 5

Parameter for Variable Perceived No. of Immigrants

Model 1

Dep Var: Too many Immigrants

Coef. Std. Error

Model 2

Dep. Var: Requirements for Accepting Inmigrants Education

$0.010 \quad(0.005) \quad *$

Family

0.006

Culture

0.007

Wealth

0.005

$(0.004) *$

Labor Requirements

0.0002

Model 3

Dep. Var: Number of Social and Political Rights

$-0.006 \quad(0.003) \quad *$

Model 4

Dep. Var: Number of Economic Benefits

$-0.012 \quad(0.005) \quad * \star$

For each model the usual independent variables are included as controls.

For the method of estimation of each model refer to the previous tables. 
Table A-1 Descriptive Statistics

\begin{tabular}{|c|c|c|c|c|c|}
\hline Variable & No. Valid Obs & Mean & Std. Dev. & Min. & Max. \\
\hline \multicolumn{6}{|l|}{ Dependent Variables } \\
\hline Too Many Immigrants & 2396 & 2.58 & 0.56 & 1 & 3 \\
\hline \multicolumn{6}{|l|}{ Requirements for Acceptance } \\
\hline Education & 2351 & 5.62 & 3.02 & 0 & 10 \\
\hline Family & 2338 & 4.74 & 3.10 & 0 & 10 \\
\hline Culture & 2413 & 3.08 & 2.45 & 0 & 10 \\
\hline Wealth & 2337 & 1.80 & 2.59 & 0 & 10 \\
\hline Labor Requirements & 2363 & 6.40 & 2.92 & 0 & 10 \\
\hline No. of Social and Political Rights & 1728 & 6.35 & 2.27 & 0 & 8 \\
\hline No of Economic Benefits & 2335 & 1.81 & 0.48 & 0 & 2 \\
\hline \multicolumn{6}{|l|}{ Explanatory Variables } \\
\hline Male & 2485 & 0.49 & 0.50 & 0 & 1 \\
\hline Age & 2484 & 46.03 & 18.10 & 18 & 92 \\
\hline \multicolumn{6}{|l|}{ Schooling } \\
\hline Elementary Completed & 2476 & 0.22 & 0.41 & 0 & 1 \\
\hline Basic Secondary & 2476 & 0.30 & 0.46 & 0 & 1 \\
\hline Higher Secondary & 2476 & 0.22 & 0.41 & 0 & 1 \\
\hline Technical & 2476 & 0.08 & 0.27 & 0 & 1 \\
\hline Superior & 2476 & 0.10 & 0.29 & 0 & 1 \\
\hline Married & 2483 & 0.58 & 0.49 & 0 & 1 \\
\hline Catholic & 2441 & 0.81 & 0.39 & 0 & 1 \\
\hline Blue-Collar Worker & 2485 & 0.47 & 0.50 & 0 & 1 \\
\hline Service Worker & 2485 & 0.36 & 0.48 & 0 & 1 \\
\hline Unemployed & 2485 & 0.09 & 0.29 & 0 & 1 \\
\hline Province Immig. Rate & 2485 & 8.95 & 5.14 & 1.9 & 20.1 \\
\hline \% Moroccan Immigrants & 2485 & 12.85 & 8.18 & 2.9 & 56.0 \\
\hline GDP Per Capita (000s Euros) & 2485 & 22.99 & 4.60 & 15.6 & 30.0 \\
\hline Regionalistic Community & 2485 & 0.28 & 0.45 & 0 & 1 \\
\hline "Wages fall..." & 2344 & 3.10 & 1.30 & 1 & 5 \\
\hline "Impact on Poor..." & 2347 & 3.66 & 1.16 & 1 & 5 \\
\hline "Labor needed..." & 2360 & 3.60 & 1.10 & 1 & 5 \\
\hline Preference for Diversity & 2371 & 2.12 & 0.93 & 1 & 4 \\
\hline Rejects other Races & 2341 & 2.67 & 3.25 & 0 & 10 \\
\hline Work Contact & 2444 & 0.41 & 0.49 & 0 & 1 \\
\hline Neighbor Contact & 2429 & 0.32 & 0.47 & 0 & 1 \\
\hline Frienship Contact & 2425 & 0.37 & 0.48 & 0 & 1 \\
\hline Perceived No. Immigrants & 1698 & 9.44 & 16.46 & -10 & 79 \\
\hline
\end{tabular}


Table A-2 Correlation among Dependent Variables

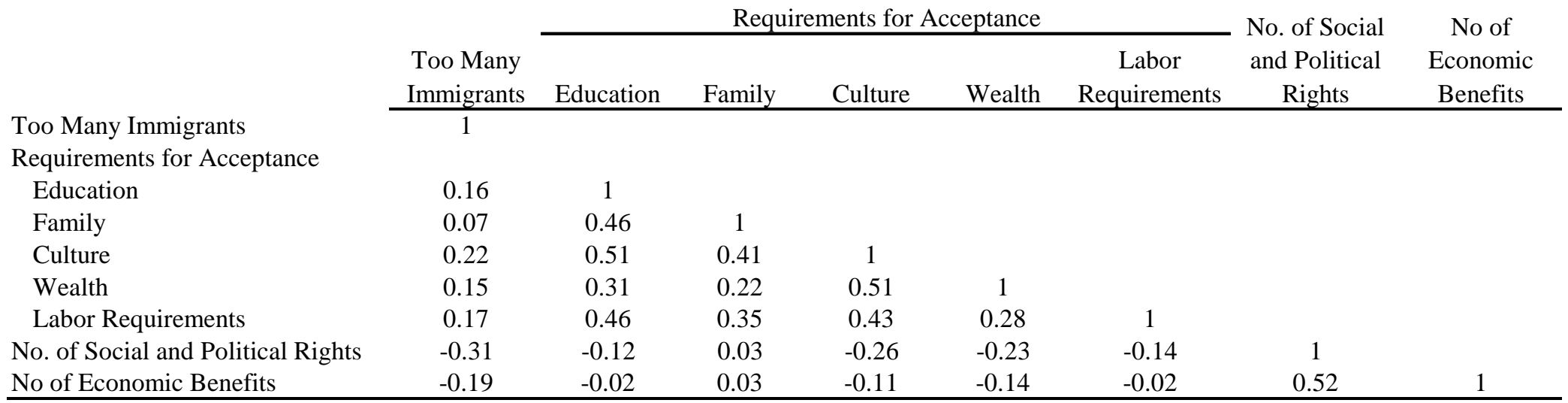

